Housing Studies

\title{
At home in home care? Contents and boundaries of the 'domestic' among immigrant live-in workers in Italy
}

\section{Paolo Boccagni}

To cite this article: Paolo Boccagni (2018) At home in home care? Contents and boundaries of the 'domestic' among immigrant live-in workers in Italy, Housing Studies, 33:5, 813-831, DOI: 10.1080/02673037.2017.1367366

To link to this article: https://doi.org/10.1080/02673037.2017.1367366

曲 Published online: 04 Sep 2017.

Submit your article to this journal $\widetilde{ }$

Џ Article views: 121

Q View related articles $\widetilde{ }$

View Crossmark data $\asymp$ 


\title{
At home in home care? Contents and boundaries of the 'domestic' among immigrant live-in workers in Italy
}

\author{
Paolo Boccagni \\ ERC StG HOMInG-University of Trento, Trento, Italy
}

\begin{abstract}
How 'at home', if at all, migrants feel in their everyday lives abroad is a neglected research issue, with meaningful implications for immigrant, social and housing policies. Their employment as live-in care workers with elderly clients is a unique site to address it, as this article aims to do, based on an archive of life histories of immigrant women in Italy. Co-residential domestic work foregrounds migrants' need for a domestic space of their own, within the place of someone else. Building on immigrant women's narratives, I explore what senses and dimensions of domesticity, or even of home, are negotiated in their routine interactions with older clients and the latter's family members. Within a dwelling place which conflates work and domesticity, the cognitive, emotional and practical dimensions of migrants' gendered home experience are nothing obvious. How is home-making - as a set of practices oriented to pursue security, familiarity and control - enacted under these circumstances? Is the cultivation of a sense of home beneficial to the clients only, or do immigrant women themselves feel at home somehow? Different 'modes of domesticity' are discussed, at the intersection between continuous expectations of home-making and discontinuous ways of feeling at home.
\end{abstract}

\section{ARTICLE HISTORY}

Received 16 May 2016

Accepted 7 August 2017

\section{KEYWORDS}

Home-making; feeling at home; immigrant women; live-in care work; domesticity; Italy

\section{Introduction}

Getting access to decent dwelling arrangements, for immigrant newcomers, is a notoriously difficult and often unaccomplished process. Feeling at home there, possibly retaining some continuity with the home experience of the past, may be a still more challenging issue, which is also revealing for immigration, welfare and housing policies. Most notably, if 'there' happens to be their workplace, and simultaneously the home of someone else, a peculiar dwelling condition emerges; one, epitomized by live-in immigrant care workers, in which the attempt to recover domesticity matches with the task to support the domesticity of another person: the elderly dependent client, whose ageing-in-place is what requires immigrant workers' recruitment (Chiatti et al., 2013). How far immigrants themselves feel at home in this thick relational setting - i.e. attach a sense of security, familiarity and control to it (Boccagni, 2017) - is the question to be investigated in this article. If large-scale migration 
affects one's home experience anyway, a home care setting makes for a valuable research field on the potential recreation of domestic space, far away from the past ones.

In countries with limited public investment in long-term care, such as Italy (Da Roit, 2007), co-residential care work enables cheap, if temporary accommodation for low-paid immigrants, perceived as 'suitable' along well-defined ethno-cultural and gender lines (Degiuli, 2007; cf. Anderson, 2007; Doyle \& Timonen, 2010). It also results, though, in a scarcely 'homelike' setting - one marked by strong segregation, lack of private spaces and a tacit but pervasive expectation of 'asymmetric familiarity' from the employer side. My contribution revisits this dwelling and relational arrangement in terms of home-making and feeling-at-home, building on an archive of in-depth interviews with immigrant domestic workers all across Italy (Catanzaro \& Colombo, 2009). Out of this extensive data-set I selected and analyzed 165 interviews, based on gender (only women), working condition (live-in jobs) and membership of the six national groups which most contribute to immigrant domestic labour in Italy (i.e. Filipinos, Ukrainians, Ecuadorians, Peruvians, Romanians and Poles).

This article aims to explore, first, how far immigrant domestic workers negotiate a domestic space of their own; second, what sense they make of it, depending on their interactions with care recipients and on their working and dwelling conditions. The biographical archive on which I build is a rich source of information on respondents' views and feelings about home, care and the domestic, under the influence of environmental factors such as the organization and accessibility of domestic spaces; the regulation of social distance with their counterparts; the utilization of material objects or symbols with some potential to recall or reproduce their past sense of home. Consistent with the latter aspect, migrants' transnational and local networks are also interrogated as a source of home feelings.

The paper first reviews the recent debate on home and migration, against the background of immigrant live-in paid care in Italy. It then explores the ambiguous forms of domesticity that emerge within the dwelling places of immigrants' elderly clients, eventually emphasizing the tension between migrants' home-making tasks (to the benefit of someone else) and their own ways of feeling little, if at all, at home. The very notion of home is critically unpacked in ways that highlight the gap between its romanticized normative contours and the unhomely circumstances of the actual domestic experience. A typology of 'modes of domesticity' in the context of live-in paid care is then advanced, prior to some conclusive remarks on the migration-home nexus and on the implications of this case study.

\section{Immigrant women, care work and the elusive experience of home}

Over the last decades, home care to the elderly has been a source of increasing employment for immigrant, mostly female labour in Italy (Ambrosini, 2013; Rusmini \& Pasquinelli, 2015) and, to variable degrees, elsewhere in Europe (Doyle \& Timonen, 2010; Kilkey et al., 2010; Lutz, 2011). Live-in care work, in particular, stands out as a strongly ethnicized and feminized niche. It is primarily chosen by newcomer middle-aged women, with most of their family members in the countries of origin and an initial expectation of short-term permanence abroad (Da Roit, 2007; Di Rosa et al., 2012). While this dwelling configuration is by now quite widespread and perceived as 'normal' in the country, little research exists on its implications in a home perspective - particularly when it comes to the subjective experience of care workers themselves (see, among exceptions elsewhere, Ceci et al., 2012; England, 2010). 
In fact, what home means to distinct dwellers in the same domestic space is nothing obvious. If this holds for different members of the same household (whose home experience can diverge along lines of gender, age and generation [Mee \& Vaughan, 2012]), it is still more the case within the relation between native elderly dwellers and paid immigrant caregivers. Yet, their respective views, feelings and practices of home have much to say on their mutual interaction (hence on the enactment of care work), and contribute to shape it, in turn. My study, therefore, aims to start filling the gap of knowledge on the conflicting emotions, relationships and practices associated with home, against the segregated, gendered and ethnicized background of live-in care work.

The popular notion of home has been widely used and discussed across social sciences, despite, or possibly because of its ambiguity (e.g. Altman \& Werner, 1985; Benjamin \& Stea, 1995; Miller, 2001; Morley, 2000). Unsurprisingly for such a slippery and value-laden notion, home can be stretched in several conceptual directions, depending also on the 'personal meanings' it is 'imbued with ... at different times and in different contexts' (Easthope, 2004 , p. 135). Home may equally apply to a presently emplaced life experience and to one's memories of, or desires for, a life setting better than the present one, and far away from it. Real and ideal (or idealized) stances are equally significant, and sometimes indistinguishable from each other, for the social understanding of home. Admittedly, this debate entails a risk of romanticizing the very notion of home, while underplaying the specific historical, social and economic determinants of the (currently hegemonic) ideal of the private home (Blunt \& Dowling, 2006). Nonetheless, it is important to find out how domestic life works out in practice; what forms of inequality and violence it may conceal; what sense social actors make of it, against their own view of what a proper home should look like.

The home debate is also clearly relevant to migration studies, in light of the changing relations between space, identity and belonging that shape migrants' trajectories (Ahmed et al., 2003; Ralph \& Staeheli, 2011; Rapport \& Dawson, 1998). Quintessential to the migrant experience is an extended detachment from previous home places and communities. This results in the need for a new dwelling place and possibly in the hope for better dwelling arrangements in the future, whether in host- or in home-lands. As pervasive is migrants' tension to recover significant aspects of what used to be their home, and to negotiate new meanings, senses and practices of it, while they make their way through receiving societies (e.g. Duyvendak, 2011; Korac, 2009; Boccagni \& Brighenti, 2017).

Sociologically speaking, home can be defined as an emotionally laden social relationship with particular places (Dovey, 1985; Kusenbach \& Paulsen, 2013; Mallett, 2004); put differently, as the tentative appropriation of one or more places as a distinctive source of security, familiarity and control (Boccagni, 2017). While being tied to particular material settings, the notion of home points to a source of personal (and household) identity, with meaningful emotional and affective bases, as well as relational ones. Less obviously, home holds a performative dimension - i.e. home-making - standing for the processes through which 'space and time are structured functionally, economically, aesthetically and morally' (Rapport \& Dawson, 1998, p. 6), and one's control over a given space, to be relabelled as home, is cultivated over time (Douglas, 1991).

Following the last point, the tentative emplacement of home in a live-in care setting can be preliminarily explored through the more humble and pragmatic notion of domesticity. This is a descriptor of the ways in which the living places of care recipient elderly, and their everyday routines, are domesticized - that is: experientially learnt and subject to mutual functional adaptation - within a proximate relationship of care. 
Compared to any other background to migrants' home-making, live-in paid care is unique for the workers' all-encompassing, if transitory permanence within a bounded place that is already clearly marked as home for its native dwellers. What this entails for the home experience of co-resident immigrants is less clear. The Italian casa, to be translated as home or - more often - house or dwelling, is unsurprisingly frequent in the self-narratives of the live-in immigrant employees. It may be associated with their segregative work setting - even 'a prison', for some of them. It may stand as a marker of their need of intimacy, autonomy and security. It is also, and often simultaneously, a powerful way of displaying their predominant identification with other places and/or people, most of them still being in their home societies.

All these meanings and emotional stances may have a limited overlapping with the actual dwelling place of these respondents. In fact, there is nothing obvious in exploring the constructions and implications of the idea of home underlying immigrant-provided home care work. While the practice of home care has been the subject of increasing research, even from within 'home studies', the home-related views and emotions of those who are expected to enact it have hardly been studied - even less so for gendered and ethnicized care providers, in the intricacies of a live-in setting. An in-depth revisit of these narratives is necessary to appreciate, first, their ways of feeling towards their dwelling-and-working place, on a continuum between a basic sense of domesticity and a more inclusive and rewarding sense of home; second, the ways of coping with the tension between their expected function of home-makers (to someone else) and the residual scope for them to feel at home. Besides analyzing the variety of meanings associated with the word casa, I look at what these narratives show about the access to the domestic setting and the negotiation of proximity, intimacy and familiarity inside it.

\section{A case study of immigrant care workers in Italy}

The empirical basis for this article is provided by 165 in-depth interviews with immigrant women involved in live-in paid care with elderly clients. This is a subset of a broader archive of about 680 life histories of immigrant domestic workers, collected all over Italy between 2005 and 2007 (Catanzaro \& Colombo, 2009). Since then, the demand for cheap and feminized immigrant labour in home care to the elderly has hardly diminished - not even under circumstances of extended recession, from 2008 onwards (ISTAT, 2014).

This nation-wide data-set was the outcome of a purposive sampling research design, based on a variety of entry points but following well-defined selection criteria in terms of gender, length of stay, domestic work arrangement (live-in or not), city size and geographical area. While not aiming to statistical representation, this study has resulted in an unprecedentedly rich archive of migrants' life stories in Italy. My content analysis, conducted with the software N-Vivo, was intentionally limited to female live-in care workers from the six countries with the highest share of co-residential work among respondents (165 cases overall). The relevant countries of origin and key demographics are as follows: Ecuador (7\% of interviewees, mean age 41 yrs., mean length of stay in Italy 6 yrs.); Peru ( $10 \%$ of interviewees, mean age 34 , mean length of stay 7$)$; Poland ( $22 \%$, mean age 40 , mean length of stay 8 ); Philippines (13\%, mean age 45 , mean length of stay 13 ); Romania (23\%, mean age 40 , mean length of stay 3 ); Ukraine (25\%, mean age 47 , mean length of stay 6 ). This has resulted in a subgroup of interviewees settled all over Italy, albeit with a stronger 
concentration in large metropolitan areas - such as Rome, Milan, Naples and Turin - as is typical of domestic work in this country.

While their group differences in mean age and length of stay cannot be regarded as statistically significant, they do say something on the underlying demographics. Among the immigrant groups considered here, Filipinas are those with the longest record in domestic work in Italy; the case of Ukrainians is unique for the extent to which women outnumber their younger (and male) counterparts; Ecuadorians, Peruvians and Poles are all groups with a majority of relatively young immigrant women, while Romanians were newcomers in the middle 2000s - their presence in the country having significantly increased only after the 2007 EU enlargement (IDOS, 2015).

All interviewees' names in this article are fictitious, to protect their privacy. The bulk of each interview covered migrants' past biographies, their family ties and their work careers, most notably in the domestic sector. While respondents' subjective experience of home was not an explicit research focus, it did emerge as a constant background to their narratives, since participants were asked to describe their housing trajectories, as well as the everyday routines within their dwelling-and-working place. This has produced a wealth of information on their home-related views and practices, as enacted in a particularly 'thick', segregated and potentially oppressive home environment.

Of course, this interview archive is not without limitations. It builds on the secondary analysis of self-narratives that were collected (in Italian) and verbalized under circumstances that lie out of the control of my ex-post revisit (cf. Seale [2011] for an assessment of the pros and cons of this kind of analysis). Moreover, any self-biographic narrative holds some risk of overly shifting the focus of attribution to the respondent's personal qualities and powers. In this case, the risk may lie in overemphasizing interviewees' autonomy in decision-making, in managing the everyday life routines of older clients and so forth; in other words, in conveying an image of strongly independent workers, within a work setting which typically leaves little room for autonomy. As important, this source says nothing, unless through the workers' narrative mediation, of the constructions and the sense of home of elderly clients themselves - an issue that has been addressed within research on home care (Dyck et al., 2005), even with immigrant or ethnic minority care providers (England \& Dyck, 2012). Last, this interview archive cannot be - and did not aim to be - statistically representative of the correspondent population, all across the country.

As a result, my analysis aims at societal rather than statistical significance (Fitzgerald, 2006), by undelving a number of questions relevant to the intersection between housing, migration and care studies. At the same time, the limitations inherent in the data source have required much caution in any generalization on the relevance of respondents' ethno-national background. Of course, the recruitment of immigrant care workers is a heavily ethnicized and gendered practice. That said, nationality is just as relevant as other variables, such as age, education or length of stay, in accounting for respondents' potential to feel at home. This is also affected, of course, by the material, emotional and relational circumstances of their new dwelling environment.

Overall, this narrative archive provides a wealth of fine-grained details on the subjective side of the home experience (Blunt, 2003); more specifically, on respondents' evolving sense of home in the face of an extended detachment from the homeland, and of their domestic obligations towards vulnerable clients and their family members. For sure, home-related attitudes and practices are also affected by their broader migration, working and housing 
careers, and even by the deep-rooted 'cultures of domesticity' in the countries of origin (see, among others, Giorgi \& Fasulo, 2013; Gram-Hanssen \& Bech-Danielsen, 2012). However, this article will primarily focus on their day-to-day negotiation of the boundaries of domesticity - across major divides such as worker vs. client, native vs. alien, dweller vs. guest - in a context of intensive and highly constrained interaction.

More often than not, the dwelling/working settings described in these narratives are transient and ephemeral. Over time, though, such a cumulative experience is far from ephemeral. It marks extended segments of the respondents' biographies and, at an aggregate level, it results in a pervasive and enduring phenomenon; sociologically speaking, in a privileged research setting on the shifting boundaries and meanings of home in everyday life.

\section{Live-in care work as negotiation of domesticity}

Round-the-clock home care work with elderly clients is embedded in distinctive material, relational and emotional circumstances. It is important to discuss them, as they critically affect the potential for immigrant workers to feel at home there. Migrants' paid care is implicitly oriented to restore the sense of home of their clients. As such, it requires an everyday fine-tuning with the expectations of their counterparts, and of adaptation to the constraints emerging in their dwelling place. Immigrant workers have to assimilate into the domesticity of their employers, with apparently little scope to affect it - a stepwise process, in terms of intensity and expected degrees of proximity, to be analyzed through their own narratives.

\subsection{Gaining access to the home}

Live-in informal care to the elderly, over the last 15 years, has provided immigrant women with a relatively easy channel into the Italian labour market (Ambrosini, 2013). Practically speaking, however, access to this work niche needs to be negotiated anew at the outset of every live-in experience. Entering the dwelling place of elderly clients is a critical and under-studied step of immigrants' co-residential work. It entails a pragmatic, hard-to-predict transition across a number of divides: public vs. private, alien vs. native, impersonal vs. intimate. In fact, this is a micro-laboratory on the emergence of social interactions between natives as insiders and immigrant workers as strangers, following the well-known insights of Simmel (1971 [1908]) and Schutz (1944); or indeed, testing theoretical arguments such as Ahmed's, on the inevitable 'encounter with strangerness... even within the home' (1999, p. 340); or different again, Jacobson's (2009). p. 357) on being-at-home as a conflation of inclusion and exclusion from different angles and to different people, since 'what is «alien» for some', such as immigrant carer workers, is simultaneously ' "our own» for another', such as their elderly clients.

Whenever immigrant workers look for a live-in job, 'they must watch it first', an interviewee warns, where 'it' stands for

The granny, her flat, all the work I want to accept or not - you must watch it. When a person does not do so, it's dangerous. This is not an ordinary job ... if you take it, you must stick to it, you must behave. But you must stay here as if it is your home, with the whole of yourself, you're all here, there's no other place to go right now - you can't think of any other place. This is not a job where you come and go, this is night and day - that's very important. (Anna, Ukrainian, 47 years old, in Italy for 2yrs) 
Faced with an opportunity for live-in paid care, a prospect worker should get from the outside some glimpse of a domestic environment which is difficult to decipher, but may soon turn into an almost all-encompassing living place. Her working conditions are affected by the extent of the care-giving tasks, but also by the workload associated with the domestic space in the background; and, more elusively, by the inclusive/exclusive potential of that space.

Approaching a new domestic environment does not entail only some pragmatic accommodation between migrant workers and their counterparts, potentially turning the 'bright' boundary between them into a 'blurred' one, over time (cf. Alba, 2005). Besides that, to enter a new dwelling place, look after an older frail person and get used to their everyday routines requires some novel and accelerated socialization. This is not limited to fine-tuning with the client's idiosyncrasies, needs and expectations - and to some degree, to the latter's adaptation to the newcomer (Stacey, 2011). For sure, managing the 'body space', hence getting used to mutual corporeal proximity and even intimacy, is important. The same holds, however, for migrants' need to navigate the new 'homespace' (Dyck et al., 2005), or learn the unwritten foundations of the clients' home cultures - all of the aspects which make their dwelling place a home-like one (Van Steenwinkel et al., 2012).

Immigrant live-in carers have to make experientially sense of the homemaking routines and moralities that have tacitly crystallized into their clients' place; of the boundaries of the home spaces in which they may stay for different functions and purposes; of the appropriate ways of using domestic rooms, furniture, objects, etc.; of the distances to be respected in their interactions with care recipients. While any new dwelling may be initially perceived as an undifferentiated and anonymous one, it is in fact highly pre-structured in all of these respects, which I frame under the catchword of domesticity. Migrants' variable success in understanding it, and their room of manoeuvre in appropriating it rather than perceiving it as 'natural' and out of question or control, are also crucial to their home-making: that is, to their chances to recreate some fragments of home for themselves, within an alien domestic place.

\subsection{Proximities and boundaries: domesticity as everyday negotiation}

Even once an immigrant care worker gets settled in her new 'home', domesticity emerges as a matter to be negotiated day after day. 'I can't leave her [him] alone' was an oft-recurring sentence, as interviewees were asked about their expected tasks. Physically staying in the client's flat almost the whole day, at almost any time, is the distinctive marker of the live-in work experience - even when 'you've nothing to do, 'stay always sitting in front of the TV-set' or 'spend all the time watching passer-bys', as some interviewees put it. A requirement of 'forced proximity' holds anyway, whatever the practical tasks to support the client's corporeal needs and routines (England \& Dyck, 2011). Through this fundamental function of co-presence, live-in care givers enable recipients to retain a sense of familiarity and control of the everyday home space, under deteriorating physical conditions. This entails adaptation to the slower, apparently 'emptier' life rhythms of care recipients. It also results, though, in a severe constraint on the space and time available for workers themselves. Such a systematic and pervasive co-presence is exactly what migrant women lack, and often miss, in their relationships with left-behind kin (Bonizzoni \& Boccagni, 2014).

Under this intensive care arrangement, the same living space is shared night and day in a de facto household setting. This need not question, though, the immaterial divide between 
care providers and recipients in terms of social position, age, ethnicity and health/physical condition. While the interpersonal climate may improve over time, 'There is always a distance between us', in the blunt remark of Sofia, an Ukrainian woman in her early 50s. Role boundaries are not in question - nor is the implicit expectation that immigrant women with a certain national background be 'naturally inclined' to this job under almost any circumstance. Even too blurred is, instead, the boundary between work and non-work, or between professional and private life. This may make for a condition of hyper-domesticity, whereby the instrumental and performative dimension of home suffocates the expressive and affective one.

As Dorota notes, by revisiting almost a decade as live-in care giver (in 'only' three different households - something for which she feels 'lucky'):

The problem is just one: [in any other job], even if you work 8,10 or even $15 \mathrm{~h}$ a day, then you get back home and have your place; here, as a badante [live-in care worker], you're available $24 \mathrm{~h}$ a day, you always work in a place that is not yours, even if you have your own room [...] You know, I've got a roof over my head, I can't really complain but ... you're basically dependent on this person [her care recipient]. (Dorota, Polish, 52 years old, in Italy for 9yrs)

The mutual, if asymmetric dependence between care provider and recipient is simply constitutive of the live-in care setting. Nonetheless, judging from the narratives I analyzed, this setting also holds a potential for inclusive domesticity, depending both on the mutual confidence between workers and clients, and on the severity of the latter's health problems. How (far) immigrant workers cultivate a sense of intimacy and autonomy, however, also depends on their ways of using the domestic space. Critical in this sense is the availability of a room for themselves - as a micro-proxy of home-opposed to sleeping in the same room as the client; the access to, use or property of a TV set, a radio, a computer; the possession or lack of the keys of the flat for everyday use; the opportunity to do shopping and use bank services alone; the 'right' to have dinner and lunch together with clients, and possibly with other family members; the possibility to invite kin, friends or even partners on a more or less periodical basis.

Whether these micro-spaces of domesticity enable migrants themselves to feel at home, and what of the ensuing ambiguities, are the next questions to be addressed, by expanding on their relational position vis-à-vis clients and their kin.

\subsection{The crucial relational side: from a household to a family?}

The significance of live-in care work for migrant women's experience of home does not derive only from the overlapping between working and dwelling place. Willingly or not, this job entails also a degree of 'kin-work' (Di Leonardo, 1987). Immigrant care workers find themselves at the core of family-bound relationships, attachments and tensions, up to being framed like 'one of the family' - a particularly complex and mixed emotional experience (Nare, 2011; Parrenas, 2001; Salami et al., 2016; Stacey, 2011).

Some of the interviewees from my data archive did report feeling, quite satisfactorily, like a family member - at least in particularly 'homely' circumstances and family settings. This perceived condition conflates several dimensions: a strong sense of autonomy, ease and mutual trust; the perception of a supportive and non-judgemental attitude from the employer; the appreciation of conviviality practices such as eating together and invitations to family rituals and events (Christmas celebrations, birthday parties, etc.). This is a relatively 
infrequent development, though. A scenario of predominant engagement with frail or deteriorated elderly clients, with little institutional support and interaction with the external environment, emerges from these interviews - and from other case studies of immigrant live-in care work in Italy (e.g. Da Roit, 2007; Di Rosa et al., 2012).

Even in the best case, moreover, such a sense of relatedness is not without ambiguities, as much feminist literature has shown (Anderson, 2007). Deep familiarity may easily slide into an expected full dedication to the (superior) interest of the client and even a silent annihilation of one's needs, not to mention one's rights. After all, a family-like relationship may well build on deep power inequalities along gender, age or even ethnic lines. Feeling like one of the family is then conducive to a special, affection-laden and potentially oppressive relationship with care recipients - one that leaves little space to migrants' sense of home as a positive, albeit vague and evocative, personal condition. In the words of many interviewees, feeling like one of the family is a mixed and ambivalent experience. It points to the coexistence of opposite emotions, even to the inability to take a stand for either of them. The emotional attachment and mutual trust, which may pervade the relationship between workers and clients, are exactly what prevents the former to negotiate more autonomy vis-à-vis the latter. The narratives of two Romanian care workers, Madi and Mina, are a case in point:

I mean, granma is good, but it's hard - she's got used to me so much, she trusts me. She doesn't even stay in a room without me. If I go to my room she follows me, if I go to the bathroom she follows me. Sure, she sees me every day, I'm no more a stranger for her - I'm a part of her family, right? I'm the one who looks after her all day long, when she feels bad, when she must sleep, when... all of that, no? [...] And of course, when she's without me, she feels lost. But this is a hard thing, it's hard for a worker. It drives you crazy... one thing is to work with an older person, 4 or $5 \mathrm{~h}$ a day, but you go back home after that. But to stay here every minute, every second ... [...] Then you get used to that, you'd like to go away but then you think of her, it would be too bad, true, and all of them, her relatives, trust me so much ... it's not easy to go away although you would like to, you see what you mean? If you didn't care about her, then, it would be different. (Madi, Romanian, 36 yrs. old, in Italy for 3)

That older person was very problematic, she had a quite particular mood and ... well, I had been able to have a good relation with her, but it was painful to make her feel bad or - I didn't really care about me, I mean, I tried to ask as little her possible for her not to feel bad, rather, at worst, you sacrifice yourself ... to make her feel batter. This is nothing good, at the end you can't even recognize yourself [...]. It's all because you don't want to disappoint her, she's an old lady, I had too much respect for her. (Mina, Romanian, 34 yrs. old, in Italy for 4)

'Don't leave me alone, don't get back home, keep staying here until I die!', cries out one client, as reported in the narrative of Luba, a fifty years old Ukrainian. This is exemplary of a moral claim that may be legitimate in a framework of familial obligations, but far less so less so within a market-based transaction. The transition from a professional to a kinship-like frame, however, is exactly the output of an extended 'familization' process (Ambrosini, 2013). At least under certain conditions, then, a market-based relationship is ironically more favourable to the workers' autonomy than a family-style one. This shows how slippery and potentially manipulative the family framework is, once it is interiorized in a live-in care relationship.

Much in the same vein, interviewee's ways of framing their expected tasks as 'doing what they used to do at home' raise major ambiguities, as the next section shows. Both the family-like and the home-like discourse, while often associated with greater subjective wellbeing, have their own downsides - an issue to be discussed at the end of this article. 


\section{Home-making without feeling-at-home}

Whether the dwelling conditions described above enable immigrant women to feel at home in any sense, and how the prevalent lack of that feeling should be interpreted, are the questions to be addressed next. This will lead me to elaborate on the different 'modes of domesticity' which emerge from the interviewees' experience in live-in care work.

\subsection{Reproducing an un-homely domesticity}

'You're at disposal all the time here, you do everything in this place as it were your own place', says Maria, a Romanian paid carer of 41 . As it were, in a number of these narratives, is meant to demonstrate migrant women's dedication to their work place and care recipients. It is also a gendered marker of the consistency and continuity between their current tasks and the 'ordinary' domestic activities they used to do prior to emigration. In fact, it reveals the persistence of a traditional (and rarely questioned) female home-maker role - one which does meet a strong demand for cheap and intensive care labour, in Italy and beyond. At the same time, a statement like 'I've taken care of her home as it were my home', in the words of another interviewee, does not necessarily mean that the care worker herself feels at home there. Rather, it is telling of the interviewees' predominant estrangement from that place, and of the remoteness of their home.

This clearly illustrates the disjuncture between home-making and feeling-at-home which underlies immigrants' domestic care work. While attending to the personal care of their clients and the material care of the surrounding environment, respondents tend to remain alien to that place for all that concerns home as an 'emotional «warehouse»' (Easthope, 2004, p. 134): in terms of self-identification, emotional warmth and personal control, rather than only of basic security and protection. Of course, no work place is usually expected to engender more than that. It is however paradoxical, and possibly difficult to sustain over time, that such a lack of substantive home attributes be experienced inside a home environment:

You know, a two-room flat, a tiny place, it's difficult to share it with a person you don't feel ... you know, home is an intimate thing, you can't share it with anybody. It may be that I'm too stubborn, that I don't like anything, perhaps, but - home, to me, is a place where you must feel well, be well, you can't always live like I'm here: I can't get dressed the way I like, I can't keep sitting this way, I can't lie stretched where I like, I mean: home is a place where you can do what you like. I'd rather find a smaller place, provided it is mine, only mine ... if you aren't really friend with her [the person she lives with], you can't feel at ease either - that means this is not your home. (Brigitta, Romanian, 42 years old, in Italy for 4yrs)

Perhaps unsurprisingly for a recent flow of lone and female migrants, the warmer and deeply felt markers of the idea of home are almost exclusively associated with the local communities and families of origin. And once projected there, the notion of home - as an unquestionably 'natural' life space, contrary to the working space here - is often re-embedded into a new and better house which is being built, while migrants work far away, thanks to their remittances (Boccagni, 2014).

Over time, nonetheless, the elderly clients' place need not be totally un-homely either depending not only on the perceived quality of the personal relationships that are built there. Against the question 'Do you like the place you are in?', interviewees' response is not unambiguously negative. In terms of material and functional arrangements, this is often a better accommodation than most dwelling options accessible to immigrant newcomers. Moreover, 
as highlighted above, their working/dwelling place also holds some traits of domesticity. It is primarily a source of protection and of relative stability and security, all the more so for undocumented workers. It also resembles a certain aspect of the home experience in the sense of Douglas (1991), as it enables the structuration of everyday routines and times in very predictable ways - although immigrants' ability to define the situation according to their wishes and needs is limited. That said, and to repeat, hardly ever is it perceived as a homelike milieu. Staying, Cleaning or Cooking are invariably the verbs that go together with it. Even when immigrant care workers do have a room of their own, their relative autonomy is necessarily instrumental to the one of their clients. For instance, Ukrainian Sofia tells of 'a lady who had a house with three rooms - I could well sleep in another room, as if it was my own, but still close to her'. Likewise, several interviewees emphasize that they are expected to sleep in their room with the door always open, for whatever need clients may have overnight. This is a powerful reminder of how blurred and porous is the boundary of their own domesticity, even in a physical sense.

The perceived obligation to keep a place homely for someone else, while rarely feeling it as home to oneself, makes for a fil rouge across these narratives. Such an emotional condition would be probably less distressful if immigrant women had more space to cultivate home feelings out of the domestic place, as I discuss below.

\subsection{Feeling not at home, revisited}

The argument made so far has followed a commonsensical assumption: a stronger sense of being-at-home in the clients' place would be indicative of - even necessary to - the subjective wellbeing of immigrant care workers. Following this assumption, not feeling at home there is symptomatic of migrants' estrangement from the receiving society, or of their basically instrumental attitude towards it. However, as this study suggests, migrants' emotional and cognitive construction of home is more complex than that.

To start with, feeling-at-home need not be a dichotomous emotional state, relying exclusively on one place (Blunt \& Dowling, 2006; Duyvendak, 2011). Particularly when it comes to mobile people, the ways of feeling at home can be suitably framed as a nuanced, multi-sited and open-ended social process, rather than a static either/or condition (Ralph \& Staeheli, 2011). The relational and affective bases of this process are as or more important than its material emplacement. Home itself may be appreciated by migrants less as a bounded physical place than as a 'personal space of relations and identification' (Olwig, 1998, p. 225). In this optic, the live-in care setting is once again a source of paradoxes, as an hyper-domestic place which leaves little space for extra-domestic forms of home-making (Boccagni, 2016).

Informal sociability and associational life in the public sphere, primarily mediated by co-ethnic networks, are also central to migrants' construction and identification of home (Hondagneu-Sotelo, 2017; Law, 2001). The same holds for their potential to cultivate transnational ties with left-behind family members and friends - a particularly significant point, in recent and first generation flows of 'lone migrants' such as those of care workers in Italy (Ambrosini, 2013). However, my interviewees' accounts suggest that these sources of homeliness are little accessible, and little appreciated in their potential, under these work circumstances. While co-ethnic sociability spaces tend to be fragmented and under-participated, transnational ties are often constrained by the high costs and the limited time available for cross-border interactions, not to mention home visits. Despite their evocative 
and identificational power, neither ethnic networks nor transnational ties are likely to work as proxies of home as an everyday tangible and practised experience - or as a significant source of protection and intimacy, in ways similar to those that a physical dwelling place could elicit.

Furthermore, migrants' sense of not-feeling-at-home in the clients' place need not be only a marker of distress. Of course, it may mirror a condition of marginality and exclusion or, at least, a sense of oppression for the burden of physical and emotional care. Nonetheless, an immigrant live-in care worker may also not feel at home as a matter of emotional self-protection. This stance reflects a view of her living and working arrangement as an irremediably instrumental one; her role as simply that of a paid worker, regardless of its emotional intricacy (see the first ideal type in Table 1, below). Paid domestic care invariably pushes towards forced domesticity, and calls for continuous 'emotional labour' from the worker side (Hochschild, 1983) - all the more so under a live-in regime. However, workers' attempts at relativizing these emotional pressures and emplacing some sense of home elsewhere, successfully or not, should not go unnoticed. Not-feeling-at-home in a live-in care setting, therefore, may reflect an active claim for autonomy; in other words, an attempt to protect the expressive and non-instrumental dimension of one's life from the work one - however intimate the latter is (cf. England, 2010; Huang, 2016; Wharton, 2009).

In short, the persistency of salient boundaries in the domestic space can be appreciated in nearly opposite ways: as a marker of exclusion or discrimination, but also as a mirror of the workers' attempts at retaining their intimacy and private living. How elusive and ambivalent such attempts at detachment are in practice, is clear from a number of narratives - including, again, the one of Dorota.

I feel like one of the family ... as I'm in charge of all this. But I don't want to be one of the family! This is a job - and that's all. I do it with my all my heart but ... I don't want to feel like one of the family. I don't talk with them of my private things - well, when something comes out, I do, a little bit ... (Dorota, Polish, 52 yrs. old, in Italy for 9yrs)

\section{Discussion: live-in care work and modes of domesticity}

Altogether, these interviews suggest the coexistence between different 'modes of domesticity', as ways in which immigrant women construct and experience their working and dwelling places. A typology of these modes, of the relevant empirical indicators and of the underlying attitudes is advanced in Table 1, including also a few exemplary excerpts. By drawing a line between different modes, on a case-by-case basis, it is possible to appreciate the conditions for a home care setting to be 'homely' for both parties rather than, at best, for the clients only.

Such a working/dwelling place can be predominantly framed and acted upon by immigrant paid carers as a work, a domestic or, less frequently, a home-like setting. The work mode covers all the situations in which interviewees emphasize the boundaries of what should be an 'ordinary' job, as a way of protecting themselves from its most unpleasant aspects including risks of exploitation and emotional over-involvement. A domestic frame designs, instead, any work setting in which respondents acknowledge a degree of autonomy and protection - however provisional - that is negotiated vis-à-vis employers. Last, the home-like construction points to those experiences, admittedly rare, in which care workers and their 


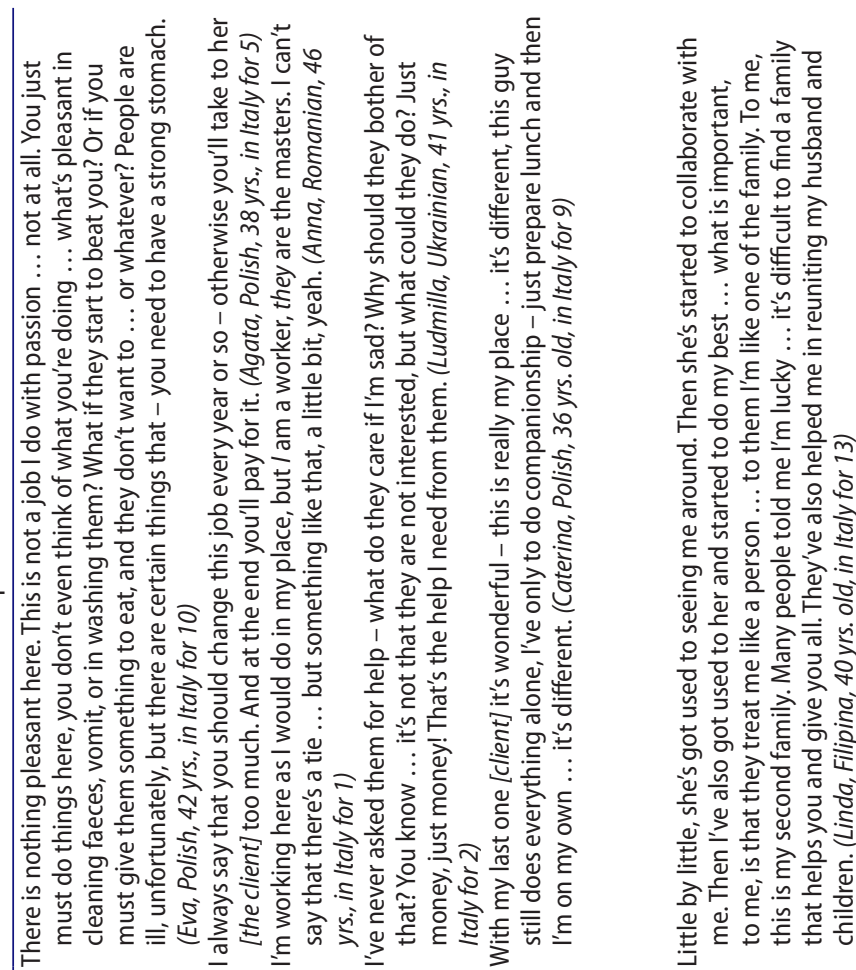

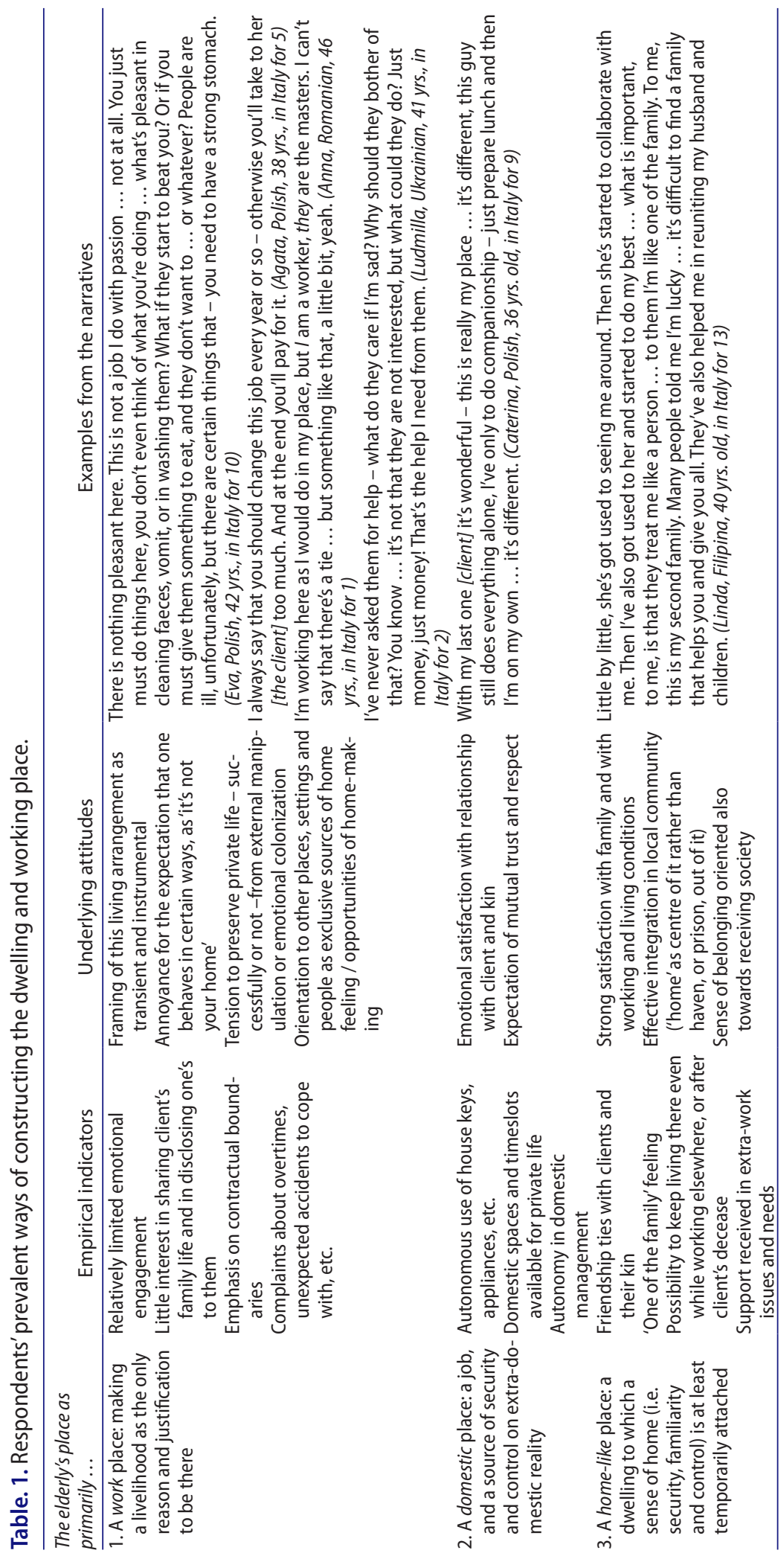


clients do develop forms of mutual friendship and support. This is what critically redefines that place as a proxy of home, at least for some time.

For sure, the typology leaves outside the cases in which no domesticity at all is experienced - reflecting openly conflictual, generally short-term relationships with the clients or the latter's family members. As important, these alternative constructions of the paid care setting do not necessarily correspond to a progressive pathway. Every new live-in experience is a story in itself, where the access to domesticity - and possibly to a deeper sense of home - is negotiated afresh. In the course of her career, the same person may construct her home/work environment in different ways, at different moments, in different households. Remarkably, though, this variable sense of domesticity is attached less to a particular built environment, than to the distinctive emotional and relational dynamics inside it.

Overall, the work-only frame is clearly the predominant one, especially at the beginning of the interviewees' migration careers - although, to repeat, their attempts at keeping the emotional sphere out of that place are often unsuccessful. Both the frames of the care site as a domestic and, even more, a home space - marked by an unusually strong relational engagement with clients and their kin - are relatively infrequent. What warrants the distinction is a different emotional intensity, and - in the case of feeling at home - a sense of intimacy and mastery which is favoured by the good relationship with the client's family, and possibly by a relatively modest care burden.

However, the 'home-like' construction is also connected with broader processes of integration in the host community. What makes the difference, then, is not the overlapping of home with the domestic environment, but rather its distribution across the receiving society, and possibly across the national boundaries with sending societies. Both the degree of openness of the dwelling/working place, and the opportunities for immigrant workers to participate in the receiving society (rather than being segregated at the margins of it), enable some of them to feel provisionally at home in the dwelling place of care recipients. No matter how infrequent or temporary, the constructions of such a place as a domestic or even home-like one are enough to go beyond the simplistic portrait of live-in care work as a necessarily un-homely experience.

That said, if home is understood - as in migrants' paradigmatic case - as a multi-sited social experience which evolves over time (that it, as homing: Boccagni, 2017), it is fundamental to grasp, first, the gap between its actual achievement and the underlying ideal standard; second, the influence of the ideal home (and of its changing constructions over space and time) on the accomplishment of the real one. The difference between what home is (felt like) and what home should (become) is clear, at least by negation, in the most reflexive self-accounts. A case in point is provided by Alina, who argues that even when a live-in worker feels treated like 'one of the family',

Work feels a bit more light - you feel a bit more like at home, although you can never feel really like that - only one thousandth of it, say, when you know that they appreciate what you're doing. (Alina, Ukrainian, 51 yrs. old, in Italy for 4 yrs.)

Once again, the subtle influence of unnecessarily romantic views of home should not go unnoticed. The very notion of home can be framed in so unrealistically and one-sidedly positive terms, to be hardly achievable as a real social experience anyway - whether for migrants or for anybody else. While potentially idealized, though, it still provides a term of reference for appreciating how remote from it - in which ways, how and why - one's dwelling circumstances are. And in the case of live-in workers, the tasks of home-making do not 
make 'home' any closer than for the bulk of first-generation immigrant newcomers - unless in the sense of having a relatively safe and protected shelter. This by no means diminishes the relevance of the immaterial side of their dwelling experience, and the need for more research into it within housing studies, as I argue in the concluding section.

\section{Conclusion}

At some point, as in the end of the narrative of Ukrainian Raisa, 'Madam died - I tidied up her place a bit and went back to my place.' This is how, in most interviews, migrants' negotiation of domesticity abruptly breaks up - the next step being a return to the communities of origin (as the only 'real home'), a search for another alien place to be turned into one's for a while or, less often, the pursuit of a different job. Temporariness, up to a sudden loss of the dwelling place due to the client's death or hospitalization, is part and parcel of live-in care work. This is bitterly ironical for a job quintessentially marked by fixity and segregation.

Yet, what occurs within that work setting is exemplary of the tension between different meanings and functions being attributed to the same dwelling - and of the need for some mediation between them. More reflection and investigation are in order on the conditions that make a dwelling place more or less home-like for different categories of dwellers, including immigrant newcomers, irreducibly to the simple distinction between owners and tenants. This opens up a major field for housing studies, theory- and practice-wise, whether regarding immigrants or other minorities. Central to it are the socio-relational and emotional aspects of dwelling (Atkinson \& Jacobs, 2016; King, 2009) - indeed, of feeling at home (Kusenbach \& Paulsen, 2013); both in themselves, and as they interact with the built environment and with the surrounding communal and public space. These immaterial dimensions of housing are clearly to be taken into account for local integration policies, including community cohesion strategies. However, they are also critical to the development of home care services. In this professional field, a better appreciation of the home-related views, routines and needs of live-in workers is essential for a more effective and sensitive service provision.

Indeed, the policy-driven emphasis on ageing-in-place has resulted in increasing attention to the infrastructural arrangements and the technological devices that are in order for elderly people to keep living 'at home'. Whenever intensive personal care is necessary, though, the situated scope for care workers to also feel at home - i.e. the influence of material and relational work conditions on their own wellbeing - can hardly be neglected. It is important to appreciate, then, that the potential benefits of an inclusive domesticity, and the downsides of a segregated one, hold for paid caregivers (including immigrant women) as much as for those they care for.

At the core of the home experience of these immigrant women lies a mixed attitude, which the expression As it were home nicely captures. This way of feeling conflates contrasting pressures: respondents' moral attachment to that dwelling place as the venue of their expected care tasks (consistent with their traditional gender identities), and their affective dis-attachment - indeed, a sense of estrangement - from the same place. The latter stance is made more salient by the distance from their home communities, and by a general paucity of spaces for cultivating their private lives and extra-work sociability. 
Having said this, one may wonder if a different dwelling arrangement would necessarily nourish a more inclusive sense of home for immigrant newcomers with few or no family ties in the host society.

In principle, different housing conditions may be more conducive to this, and allow for more opportunities to match home-making practices in and out of the domestic sphere. However, a sense of not-being-at-home in receiving societies may well persist over time - up to immigrant second generations and beyond, if we assume 'assimilation' as synonymous with feeling-at-home in the receiving society, whatever the housing condition. What sets apart the biographies of live-in immigrant workers is a more strident contradiction between their extended attempts at home-making to the clients' benefit, and their limited opportunities (or even energies) for home feeling as a personal experience.

As one reads through their narratives, different dimensions of home can be unpacked in their mutual (and conflictual) interactions: the routinization of everyday life practices (as a condition for supporting the elderly's residual autonomy), vis-à-vis the retention of one's intimacy and autonomy; the biographical continuity with the past, concerning the gendered exercise of a housewife/home-maker role, and the attempt to recover the emotional and affective bases of domestic life prior to emigration; the necessary proximity with clients, and the adaptation to their domesticity, with little scope for meaningful (hence, homely) relationships out of the domestic realm.

Such a variety of contrasting meanings could make the concept of home suspicious, either as a theoretical notion or as a policy-relevant one. However, its pervasive presence in immigrant workers' self-accounts - as an idea(l) and a set of practices - makes it hard to give it up. Rather, the diverse ways of understanding and experiencing home in these narratives call for further analytical systematization. This is no rhetorical exercise. It is, instead, a strategy for unveiling the determinants of the potential for domesticity of the very built environment - the client's home - in which personal care is emplaced. Besides being meaningful in themselves, live-in workers' narratives are telling of the practical and relational aspects of a care work setting that make it more or less tolerable, or even enjoyable. Aspects such as the workers' autonomy in using the domestic space, the availability of a separate room for their own access and control, or the possibility to invite kin and acquaintances are no background matters - they do facilitate their appreciation of the clients' place as a domestic one, if only for a while. This, in turn, enhances their positive motivations and obligations towards elderly clients and their families.

Furthermore, the workers' intimate understanding of home matters - regardless of its romanticized or normative subtext - as it shapes their ways of making clients feel still at home in their long-inhabited dwellings. In this optic, the life stories of ordinary labour migrants without strong cosmopolitan attitudes or skills, such as these interviewees, leave little room for the postmodern construction of home as an immaterial and easily portable entity, whose physical bases and boundaries would be of little relevance. Home emerges as a processual, relational and negotiated construct, but its material, place-based underpinnings - all that has to do with housing - do matter. The materiality of specific dwellings, and the degree of segregation that stems out of co-residential care, are irremediably constitutive of their own sense of home; Home-as-a-real-place, to be actually experienced or only longed for, is here to stay, and often to be missed, in migrant care workers' everyday lives.

The need to embed one's sense of home in a limited and controllable physical space, with its distinctive boundaries, lies at the centre of the homing search/need - if mostly an 
unsuccessful one - of these interviewees. At the same time, the internal characteristics of that physical space - including the relational and emotional processes in which dwellers are involved - are crucial to their experience of it as home-like; and ultimately, to the workers' success in enabling the retention of an inclusive sense of home among fragile elderly clients.

\section{Disclosure statement}

No potential conflict of interest was reported by the author.

\section{Notes on contributor}

Paolo Boccagni (Department of Sociology, University of Trento) is the principal investigator of the ERC Project HOMInG - Home as a window on migrant belonging, integration and circulation (20162021). His main research fields are transnational migration, social welfare, care, diversity and home studies. His recent publications include articles in Housing, Theory and Society and in the Journal of Housing and the Built Environment, as well as the monograph Migration and the search for home: Mapping domestic space in migrants' everyday lives.

\section{References}

Ahmed, S. (1999) Home and away, International Journal of Cultural Studies, 2(3), pp. 329-347.

Ahmed, S., Castada, C., Fortier, A.-M. \& Sheller, M. (Eds) (2003) Uprootings/Regroundings: Questions of Home and Migration, (London: Berg).

Alba, R. (2005) Bright vs. blurred boundaries: Second-generation assimilation and exclusion in France, Germany, and the United States, Ethnic and Racial Studies, 28(1), pp. 20-49.

Altman, I. \& Werner, C. (Eds) (1985) Home Environments, (New York, NY: Plenum Press).

Ambrosini, M. (2013) Irregular Migration and Invisible Welfare, (Basingstoke: Palgrave).

Anderson, B. (2007) A very private business, European Journal of Women's Studies, 14(3), pp. 247-264.

Atkinson, R. \& Jacobs, K. (2016) House, Home and Society, (London: Palgrave).

Benjamin, D. N. \& Stea, D. (Eds) (1995) The Home: Words, Interpretations, Meanings and Environments, (Aldershot: Ashgate).

Boccagni, P. (2014) What's in a (migrant) house? Changing domestic space, the negotiation of belonging and home-making in Ecuadorian migration, Housing, Theory and Society, 31(3), pp. 277-293.

Boccagni, P. (2016) Searching for wellbeing in care work migration: Constructions, practices and displacements among immigrant women in Italy, Social Politics, 23(2), pp. 284-306.

Boccagni, P. (2017) Migration and the search for home: Mapping domestic space in migrants' everyday lives, (London: Palgrave).

Bonizzoni, P. \& Boccagni, P. (2014) Care (and) circulation revisited: A conceptual map of diversity in transnational parenting, in: L. Baldassar \& L. Merla (Eds) Transnational families, migration and the circulation of care, (London: Routledge).

Boccagni, P. \& Brighenti, A. (2017) Immigrants and home in the making: Thresholds of domesticity, commonality and publicness, Journal of Housing and the Built Environment, 32(1), pp. 1-8.

Blunt, A. (2003) Home and identity: Life stories in text and in person, in: A. Blunt, P. Gruffudd, J. May, M. Ogborn, \& D. Pinder (Eds) Cultural Geography in Practice, pp. 71-90 (London: Arnold).

Blunt, A. \& Dowling, R. (2006) Home, (London: Routledge).

Catanzaro, R. \& Colombo, A. (Eds) (2009) Badanti \& Co. Il lavoro domestico straniero in Italia [Livein care workers \& Co. Immigrant domestic work in Italy], (Bologna: il Mulino).

Ceci, C., Björnsdóttir, K., \& Purkis, M. E. (Eds) (2012) Perspectives on Care at Home for Older People, (London: Routledge). 
Chiatti, C., Di Rosa, M., Barbabella, F., \& Greco, C. (2013) Migrant care work for elderly households in Italy, in: J. Troisi \& H. Kondranowitz (Eds) Ageing in the Mediterranean, (Bristol: Policy).

Da Roit, B. (2007) Changing intergenerational solidarities within families in a Mediterranean welfare state, Current Sociology, 55(2), pp. 251-269.

Degiuli, F. (2007) A job with no boundaries, European Journal of Women's Studies, 14(3), pp. 193-207.

Di Leonardo, M. (1987) The female world of cards and holidays: Women, families, and the work of kinship, Signs: Journal of Women in Culture and Society, 12(3), pp. 440-453.

Di Rosa, M., Maria, G. M., Maria, L., \& Giovanni, L. (2012) The impact of migrant work in the elder care sector: recent trends and empirical evidence in Italy, European Journal of Social Work, 15(1), pp. 9-27.

Douglas, M. (1991) The idea of home: A kind of space, Social Research, 58(1), pp. 287-307.

Dovey, K. (1985) Home and homelessness, in: I. Altman \& C. Werner (Eds) Home Environments, pp. 113-132. (New York. NY: Plenum Press).

Doyle, M. \& Timonen, V. (2010) Obligations, ambitions, calculations: Migrant care workers' negotiation of work, career, and family responsibilities, Social Politics: International Studies in Gender, State \& Society, 17(1), pp. 29-52.

Duyvendak, J. W. (2011) The Politics of Home, (Basingstoke: Palgrave).

Dyck, I., Lontos, P., Angus, J., \& McKeever, P. (2005) The home as a site for long-term care: Meanings and management of bodies and spaces, Health and Place, 11, pp. 173-185.

Easthope, H. (2004) A place called home, Housing, Theory and Society, 21, pp. 128-138.

England, K. (2010) Home, work and the shifting geographies of care, Ethics, Place and Environment, 13(2), pp. 131-150.

England, K. \& Dyck, I. (2011) Managing the body work of home care, Sociology of Health and Illness, 33(2), pp. 206-219.

England, K. \& Dyck, I. (2012) Migrant workers in home care: Routes, responsibilities, and respect, Annals of the Association of American Geographers, 102(5), pp. 1076-1083.

Fitzgerald, D. (2006) Towards a theoretical ethnography of migration, Qualitative Sociology, 29(1), pp. 1-24.

Giorgi, S. \& Fasulo, A. (2013) Transformative homes: Squatting and furnishing as sociocultural projects, Home Cultures, 10(2), pp. 111-133.

Gram-Hanssen, K. \& Bech-Danielsen, C. (2012) Creating a new home: Somali, Iraqi and Kurdish immigrants and their homes in Danish social housing, Journal of Housing and the Built Environment, 27, pp. 89-103.

Hochschild, A. R. (1983) The managed heart: The commercialization of human feeling, (Berkeley: Univercity of California Press).

Hondagneu-Sotelo, P. (2017) At home in inner-city immigrant community gardens, Journal of Housing and the Built Environment, 32(1), pp. 13-28.

Huang, S. (2016) Care work, in: D. Richardson, N. Castree, M. F. Goodchild, A. Kobayashi, W. Liu, \& R. A. Marston (Eds) The International Encyclopedia of Geography (New York, NY: Wiley).

IDOS (2015) Dossier statistico immigrazione [Statistical yearbook on immigration], (Rome: ConfrontiUNAR).

ISTAT (2014) Rapporto BES-Benessere equo e sostenibile [BES Report - Fair and sustainable wellbeing], (Rome: Istituto Nazionale di Statistica).

Jacobson, K. (2009) A developed nature: A phenomenological account of the experience of home, Continental Philosophy Review, 42, pp. 355-373.

Kilkey, M., Lutz, H., \& Palenga-Möllenbeck, E. (2010) Introduction: Domestic and care work at the intersection of welfare, gender and migration regimes: Some European experiences, Social Policy and Society, 9(03), pp. 379-384.

King, P. (2009) Using theory or making theory: Can there be theories of housing?, Housing, Theory and Society, 26(1), pp. 41-52.

Korac, M. (2009) Remaking Home. Reconstructing Life, Place and Identity in Rome and Amsterdam, (Oxford: Berg).

Kusenbach, M. \& Paulsen, K. (2013) Home: An introduction, in: M. Kusenbach \& K. Paulsen (Eds) Home, pp. 1-22 (Frankfurt: Peter Lang). 
Law, L. (2001) Home cooking: Filipino women and geographies of the senses in Hong Kong, Ecumene, 8(3), pp. 264-283.

Lutz, H. (2011) The New Maids. Transnational Women and the Care Economy, (London: Zed).

Mallett, S. (2004) Understanding home: A critical review of the literature, The Sociological Review, 52(1), pp. 62-89.

Mee, K. J. \& Vaughan, N. (2012) Experiencing home, in: S. Smith (ed.) International Encyclopedia of Housing and Home, pp. 146-151 (London: Elsevier).

Miller, D. (ed.) (2001) Home Possessions: Material Culture Behind Closed Doors, (London: Bloomsbury). Morley, D. (2000) Home Territories, (London: Routledge).

Nare, L. (2011) The moral economy of domestic and care labour: Migrant workers in Naples, Italy, Sociology, 45(3), pp. 396-412.

Olwig, K. F. (1998) Epilogue: Contested homes, in: N. Rapport \& A. Dawson (Eds) Migrants of Identity: Perceptions of Home in a World of Movement, pp. 225-236 (Oxford: Berg).

Parrenas, R. (2001) Servants of Globalization, (Stanford, CA: Stanford University Press).

Ralph, D. \& Staeheli, L. A. (2011) Home and migration: Mobilities, belongings and identities, Geography Compass, 5(7), pp. 517-530.

Rapport, N. \& Dawson, A. (Eds) (1998) Migrants of Identity: Perceptions of Home in a World of Movement, (Oxford: Berg).

Rusmini, G. \& Pasquinelli, S. (2015) Badanti e lavoro di cura: realtà e direzioni emergenti [Immigrant live-in care workers: Taking stock and emerging trends], in: S. Pasquinelli (ed.) Primo rapporto sul lavoro di cura in Lombardia, pp. 77-108 (Rimini: Maggioli).

Salami, B., Duggleby, W., \& Rajani, F. (2016) The perspective of employers/families and care recipients of migrant live-in caregivers, Health and Social Care in the Community, doi:10.1111/hsc.12330. [Epub ahead of print].

Schutz, A. (1944) The stranger: An essay in social psychology, American Journal of Sociology, 49(6), pp. 499-507.

Seale, C. (2011) Secondary analysis of qualitative data, in: D. Silverman (ed.) Qualitative Research, pp. 347-364 (London: Sage).

Simmel, G. (1971 [1908]) The stranger, in: G. Simmel (ed.) On Individuality and Social Forms, pp. 143-150 (Chicago, IL: University of Chicago Press).

Stacey, C. (2011) The Caring Self. The Work Experiences of Home Care Aides (Ithaca, NY: Cornell University Press).

Van Steenwinkel, I., Baumers, S., \& Heylighen, A. (2012) Home in later life: A framework for the architecture of home environments, Home Cultures, 9(2), pp. 195-217.

Wharton, A. (2009) The sociology of emotional labor, Annual Review of Sociology, 35, pp. 147-165. 